\title{
Immune responses to colophony, an agent causing occupational asthma
}

\author{
R T Cullen, B Cherrie, C A Soutar
}

\begin{abstract}
Background Inhalation of fumes from heated colophony (pine resin) is a recognised cause of occupational asthma, although the mechanisms by which colophony produces symptoms are unclear and specific immune responses to colophony have not been reported in sensitised workers. A study was carried out to determine whether colophony is antigenic.
\end{abstract}

Methods The immune responses to colophony were studied in C57BL/6 mice and Dunkin Hartley guinea pigs after intraperitoneal injection of colophony conjugated to bovine serum albumin (BSA) or human IgG by a mixed anydride procedure. Colophony and dinitrofluorobenzene were also compared in an assay of dermal sensitisation.

Results Mice immunised with the colophony conjugates produced antibodies which recognised conjugates of both BSA and human IgG irrespective of which had been used as the immunogen. Solutions of unconjugated colophony inhibited the binding of antibodies to the BSA-colophony and BSA-abietic acid conjugates, confirming that the antibodies recognised one or more components in the colophony. Portuguese colophony also abrogated the antigen binding of serum from guinea pigs immunised with the BSA-colophony conjugate. Spleen cells from immunised mice proliferated in the presence of the conjugates. Although there was some cross reactivity in these responses, it was not as marked as in the antibody assays. Unconjugated colophony failed to induce an immune response when injected intraperitoneally with adjuvant. Skin sensitisation could not be induced in mice by topical application, or by subcutaneous or intradermal injection of unconjugated colophony.

Conclusions Colophony components have the potential to act as haptens and an immune component could be involved in the pathogenesis of occupational asthma in workers exposed to colophony. Colophony is not readily immunogenic unless conjugated ex vivo to proteins.

(Thorax 1992;47:1050-1055)

Occupational asthma can develop after inhalation of colophony (rosin, pine resin), a natural product which is widely used as a major constituent of non-corrosive solder fluxes and in many other applications which exploit its acidic or sticky nature such as varnishes, adhesives, and paper sizes. Colophony is classified according to its country of origin and optical grade and consists primarily of a mixture of resin acids, the exact composition of which depends on its source and production method. Workers exposed to fumes generated when colophony is heated, as in soldering, are particularly at risk, ${ }^{1}$ and asthma arising from such exposure is a prescribed disease in the United Kingdom under legislation for industrial injuries compensation. However, asthma has also been reported after inhalation of unheated colophony as a dust ${ }^{2}$ or as an aerosol of cutting oils containing colophony. ${ }^{3}$ The resin acids of colophony have been implicated as the active agents, but the mechanisms of action are unknown. ${ }^{24}$ Neither skin prick tests nor serum antibody tests have confirmed an immunological component in individuals sensited to colophony. ${ }^{4}$ As immune responses may play a part in asthma associated with other low molecular weight substances, ${ }^{56}$ we have studied the immune response to Portuguese colophony-protein conjugates in mice and guinea pigs. Portuguese colophony (optical grade $\mathrm{Y}$ ) was selected since it is used by at least one manufacturer in the production of solder.

\section{Methods}

ANIMALS

The study was performed in 8-12 week old, specific pathogen free male $\mathrm{C} 57 \mathrm{~B} 1 / 6$ mice and 5 month old Dunkin Hartley guinea pigs from the Institute of Occupational Medicine breeding unit.

\section{ANALYSIS OF COLOPHONY}

The composition of any sample of colophony is dependent on the tree species producing the resin, the processing method, and subsequent storage conditions. ${ }^{78} \mathrm{~A}$ sample of Portuguese colophony (Multicore Solder Ltd, UK) dissolved in diethyl ether was analysed by gas chromatography/mass spectrometry. The gas chromatograph was fitted with a 30 metre RSL 200 capillary column programmed to heat from 55 to $260^{\prime \prime} \mathrm{C}$. Column effluent was monitored with the mass spectrometer in electron impact mode, scanning all masses between 35 and 510 daltons every second. The principal constituents were four abietic type resin acids tentatively identified by comparison with National Bureau of Standards reference mass 
Figure 1 Molecular structure of abietic acid, one of the principal resin acids in Portuguese colophony.

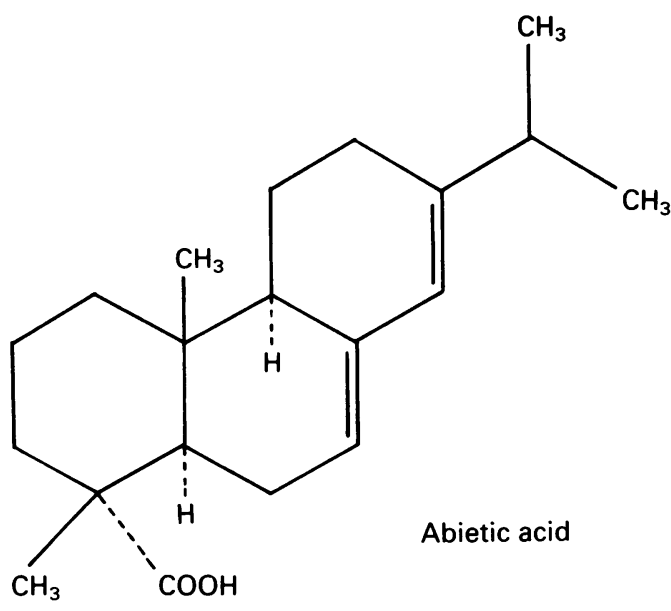

spectra as dehydroabietic, abietic, levopimaric, and palustric acids. Dehydroabietic acid formed the major component, with the other three acids in lower but roughly equal proportions. A published gas chromatograph analysis of Portuguese colophony gave abietic, palustric, neoabietic, and primaric acids as the major components. ${ }^{8}$ These differences in analyses reflect the complex and variable nature of colophony batches. The structural formula for abietic acids is shown in figure 1. Its isomers levopimaric and palustric differ only in the position of the double bonds. Dehydroabietic with two fewer hydrogen atoms has three double bonds in the upper ring.

A resin acid preparation marketed as abietic acid (Sigma Chemical Co. Ltd) was also used in some experiments. When analysed this yielded primarily levopimaric and abietic acids.

\section{PREPARATION OF CONJUGATES}

A mixed anhydride technique was adapted from a method published by Corrie $e t a l^{9}$ to exploit the carboxyl group on the resin acid component of colophony (fig 1). Portuguese colophony, $60 \mathrm{mg}$ dissolved in $1.27 \mathrm{ml}$ dimethylformamide, was cooled at $10^{\circ} \mathrm{C}$, mixed with $28 \mu \mathrm{l}$ tri-n-butylamine and $13.5 \mu \mathrm{l}$ isobutyl chloroformate (BDH) and kept at $10^{\circ} \mathrm{C}$ for 30 minutes. This was then added to an ice cold solution of $150 \mathrm{mg}$ protein (human gammaglobulin (HIG) or bovine serum albumin (BSA); Sigma) in $1 \mathrm{ml}$ water, $0.15 \mathrm{ml} 1 \mathrm{M}$ sodium hydroxide and $2 \mathrm{ml}$ dimethylformamide (Sigma). The mixture was kept on ice for 3.5 hours. Additional $\mathrm{NaOH}(400 \mu \mathrm{l})$ was added after the initial 30 minutes to reduce turbidity. The conjugate solution was then dialysed overnight against $0 \cdot 1 \mathrm{M}$ bicarbonate buffer, $\mathrm{pH} 9 \cdot 6$, and finally chromatographed on Sephadex G25 in the same buffer. The pooled fractions containing protein were analysed as described below and stored as aliquots at $-70^{\circ} \mathrm{C}$. BSA was also conjugated to a colophony labelled as abietic acid.

ANTIBODY ASSAY

A solid phase antigen assay was slightly modified from that described previously ${ }^{10}$ to measure serum antibody; $150 \mu \mathrm{l}$ volumes of conjugates or protein carriers at $100 \mu \mathrm{g} / \mathrm{ml}$ in carbonate buffer $(0 \cdot 1 \mathrm{M}, \mathrm{pH} 9 \cdot 6)$ were allowed to adhere in individual plastic microwells (Removawells, Dynatech) overnight at $4^{\circ} \mathrm{C}$. Unbound antigen was removed by washing the wells four times with assay diluent (phosphate buffered saline containing $0 \cdot 1 \%(\mathrm{w} / \mathrm{v})$ human serum albumin and $0.05 \%(\mathrm{v} / \mathrm{v})$ polyoxyethylenesorbitan monolaurate (Tween 20, Sigma)) and $150 \mu \mathrm{l}$ aliquots of test serum diluted $1 / 10,1 / 100$, and $1 / 1000$ were added to the wells. Following incubation at $37^{\circ} \mathrm{C}$ for 1 hour, the wells were washed four times in assay diluent and antibody detected by the addition of $150 \mu \mathrm{l}$ iodine-125 labelled protein A (Sigma), which adheres to the Fc region of immunoglobulins. Radiolabelled protein A was prepared as described previously. ${ }^{10}$ Approximately $10^{5}$ counts per minute were added to each well and, after incubation at room temperature for 1 hour, the wells were washed four times in assay diluent and the remaining radioactivity was determined by counting in a spectrometer (Rackgamma II, LKB). The results are presented as the mean counts per minute from triplicate wells. This method provides a general measure of antibody activity although binding of protein A to murine IgG subclasses $2 \mathrm{a}, 2 \mathrm{~b}$ and 3 will predominate.

\section{COMPETITIVE INHIBITION OF ANTIBODY}

BINDING BY COLOPHONY

The ability of colophony to interfere in the binding of serum to colophony conjugates was also studied. Diluted sera (1/25) from mice immunised to BSA-colophony or BSA-abietic acid conjugates were preincubated at $37^{\circ} \mathrm{C}$ for 30 minutes in $0 \cdot 1 \mathrm{M}$ sodium carbonate containing Portuguese colophony or abietic acid (100 $\mu \mathrm{g} / \mathrm{ml}$ final concentration). The binding of these treated sera to colophony conjugates was compared with the binding of sera treated with the carbonate solvent alone.

Because of the limited quantities of mouse serum available, competitive inhibition of antibody binding was further studied on serum from two guinea pigs immunised with the BSA-colophony conjugate. Sera diluted 1/30 or $1 / 150$ were preincubated as above with concentrations of colophony varying from 3.91 to $250 \mu \mathrm{g} / \mathrm{ml}$ (final).

\section{SPLEEN CELL ASSAY}

Single cell suspensions of spleens were prepared using a loose fitting glass homogeniser, washed twice in RPMI-1640 medium (Gibco) and finally suspended to $4 \times 10^{6} / \mathrm{ml}$ in the same medium supplemented with $5 \%$ horse serum, 5 $\times 10^{-5} \mathrm{~mol} / 1$ mercaptoethanol, and $100 \mu \mathrm{g} / \mathrm{ml}$ kanamycin (cRPMI). One hundred microlitre volumes of cell suspension were incubated with $100 \mu \mathrm{l}$ of conjugates diluted to 200,50 , or $5 \mu \mathrm{g} /$ $\mathrm{ml}$ in cRPMI in 96 well microtitre plates for five days. Antigen driven lymphocyte proliferation was determined by the incorporation of the DNA precusor tritiated thymidine (Amersham International) added for the final 16 hours of culture. Cells were harvested on to glass fibre discs (Ilacon Sheet Processor), which were placed in plastic vials and air dried before the addition of scintillation cocktail (Unisolve $\mathrm{E}$, 
Koch Light). The uptake of tritium labelled thymidine was measured in a Philips PW4700 liquid scintillation counter.

\section{PROTOCOL}

\section{Immunisation}

Mice (six per antigen but ten for BSA-colophony) received an initial intraperitoneal injection of alum precipitated conjugate $(200 \mu \mathrm{g})$ mixed with Bordetella pertussis vaccine (Wellcome) followed by booster injections of $4 \mu \mathrm{g}$ alum precipitated conjugate alone four, six and eight weeks later. Animals were killed eight days after the final antigen injection and serum was taken for antibody assay and spleens for the lymphocyte mitogenic assay. Mice were also immunised with BSA and male Dunkin Hartley guinea pigs (two per antigen) were immunised with BSA or BSA-colophony conjugate with this protocol. Attempts were also made to immunise mice with unconjugated colophony dissolved in sodium carbonate $(0 \cdot 1 \mathrm{M}, \mathrm{pH} 8 \cdot 5)$ and mixed with Freund's complete adjuvant. No animals died as a result of the immunisation treatments.

\section{Dermal sensitisation}

Two experiments were conducted in which mice were lightly anaesthetised with ether and $60 \mu \mathrm{l}$ of a $0.5 \%(\mathrm{w} / \mathrm{v})$ solution of Portuguese colophony in a 1:1 mixture of acetone and olive oil was applied to one shaved flank of each of six mice. Ear thickness was measured under anaesthesia with a spring loaded paper gauge (Mitutoyo, Japan); the mean of readings from two areas near the edge of each ear pinna was recorded. Two other groups of six mice were also included, a positive control using the potent skin sensitiser dinitrofluorobenzene (DNFB, Sigma), and a control to monitor any effects of the acetone/oil vehicle. The applications were repeated on the following day. Four days later mice were challenged by applying 10 $\mu \mathrm{l}$ of the relevant test agent to the dorsum of

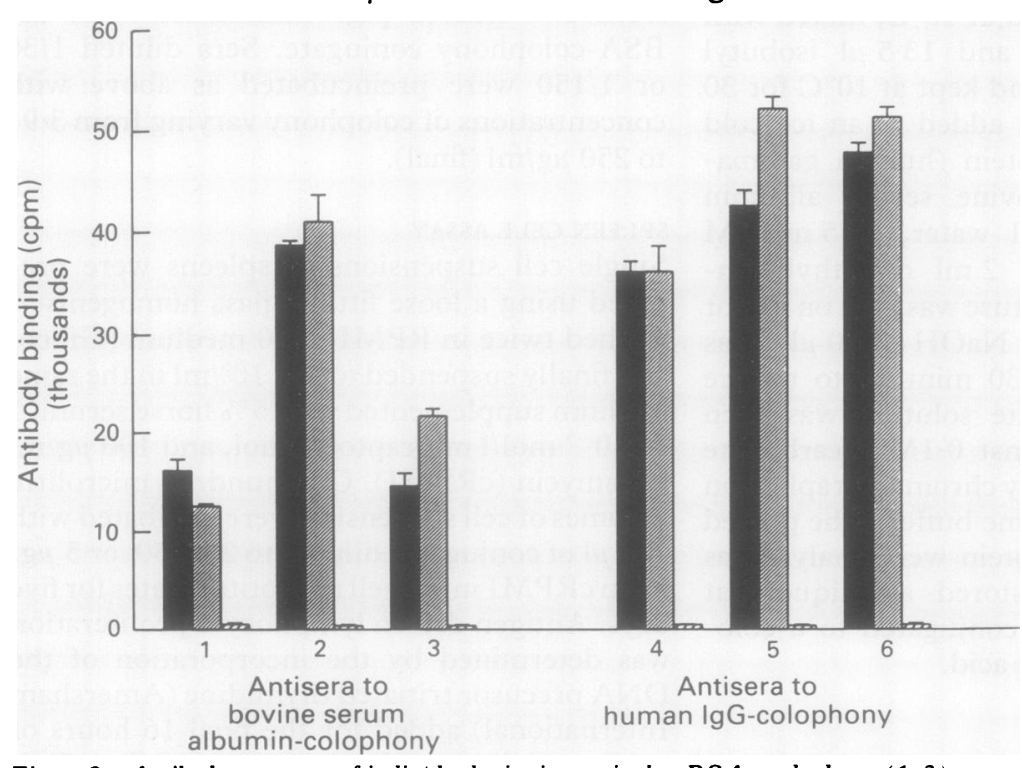

Figure 2 Antibody responses of individual mice immunised to BSA-colophony (1-3) or HIG-colophony (4-6). Results, as mean (SEM) of triplicate readings, show binding of antisera (diluted 1/10) to both BSA-colophony (D) and HIG-colophony ( $⿴$ ) conjugates but very little binding to bovine serum albumin (四). These effects were also seen with sera diluted 1 in 100. Similar results were obtained in another experiment. both ear pinnae. Changes in ear thickness were recorded 24 and 48 hours later and results were examined for significance in a paired Student's $t$ test.

In another experiment, the effect of the immunosuppressive drug cyclophosphamide on sensitisation to colophony was studied. Twelve mice were injected intraperitoneally with $6 \mathrm{mg}$ cyclophosphamide in saline two days before skin painting and subsequent challenge was as described above.

In a further group of experiments, $25 \mu \mathrm{l}$ of a solution of colophony $(0.5 \mathrm{mg} / \mathrm{ml})$ in $0.1 \mathrm{M}$ bicarbonate buffer ( $\mathrm{pH} \mathrm{8.0)}$ were injected subcutaneously or intradermally into flank skin on three occasions spaced at 21 day intervals in order to extend the induction period (12 mice per treatment group). Subsequent challenge to the ears was as described above.

\section{ANALYSIS}

Results from experiments on the inhibition of antibody binding by colophony or abietic acid were examined for significance by analysis of variance.

Data from the spleen cell proliferation experiments, as counts per minute of radioactivity incorporated, were $\log$ transformed and then expressed as mitogenic indices (logarithm of counts in the presence of antigen minus logarithm of counts in absence of antigen). The mitogenic indices were examined initially by analysis of variance and then further comparisons between groups were made with Student's $t$ tests by means of the pooled standard deviation. Changes in ear thickness in the dermal sensitisation studies were examined for significance in paired Student's $t$ tests.

\section{Results}

ANTIBODY RESPONSES

No specific antibody responses were detected in mice treated with unconjugated colophony. Antibody responses in mice to two conjugates, colophony-HIG and colophony-BSA, are shown in figure 2. Antisera from each group of mice recognised both conjugates, which indicates a common antigenic determinant, presumably the resin acid component in Portuguese colophony. Binding to BSA alone was very poor at only two to three times the background levels. This was due, in part, to the cross reactivity between BSA and the blocking antigen human serum albumin used in the assay diluent. HIG could not be used as an antigen in this assay since it binds protein A. This was not a problem with colophony-HIG.

To confirm that the antisera were recognising a colophony component on the conjugates, the ability of colophony to compete with the conjugates in binding antibody was examined. Diluted sera $(1 / 27)$ from individual mice immunised with BSA-colophony or BSAabietic acid conjugates were preincubated for 30 minutes in $0 \cdot 1 \mathrm{M}$ sodium carbonate $(\mathrm{pH} \mathrm{9.0})$ containing Portuguese colophony or abietic acid. The carbonate solvent itself had no effect on antiserum activity. Both Portuguese colophony and abietic acid reduced the binding of 


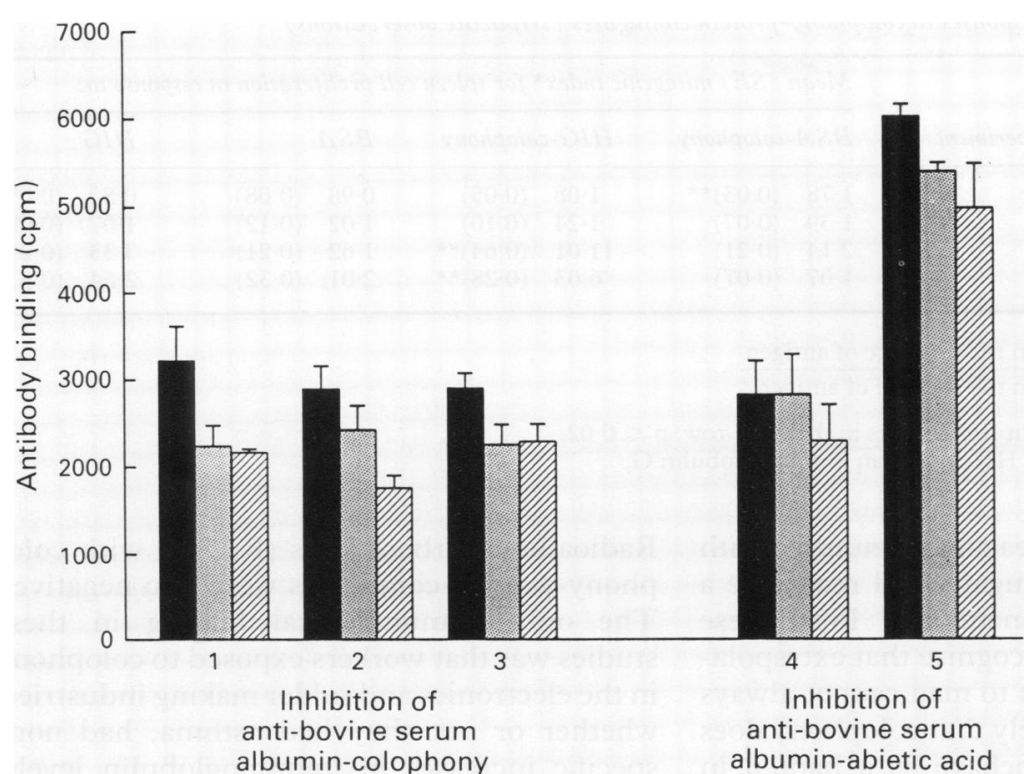

Figure 3 The effect of solutions of Portuguese colophony (国) or abietic acid (四) on the binding to antigen of three anti-BSA-colophony sera (1-3) and two anti-BSA-abietic acid sera (4 and 5). Untreated sera are shown as solid bars (1). Antibody binding is given as the mean (SE) of triplicate readings, serum diluted 1 in 27. immunised with the BSA-colophony conjugate are shown in figure 3 together with results from two mice treated with abietic acid conjugate. The extent of inhibition of binding varied between sera from $16 \cdot 1 \%$ to $39.3 \%$ for the BSA-colophony sera and from $0 \%$ to $35.9 \%$ for the BSA-abietic acid sera. The reduction in binding was statistically significant for the BSA-colophony sera ( $p<0.008$ with colophony and $p<0.001$ with abietic acid).

Inhibition of antibody binding by a range of colophony concentrations (3.91-250 $\mu \mathrm{g} / \mathrm{ml})$ was investigated with two guinea pig antiBSA-colophony sera. The resulting concentration dependent inhibition of antibody binding for one serum is shown in figure 4. Antiserum from a second guinea pig was inhibited less with only a $43 \%$ reduction in binding with the highest concentration of colophony (serum at $1 / 30$ ). This inhibitory activity of colophony was not a non-specific effect since it did not affect the binding of a guinea pig anti-BSA serum to BSA (figure 5), or the binding of goat anti-HSA to HSA (data not shown).

Figure 4 The effect of solutions of unconjugated colophony on the binding of guinea pig anti-BSAcolophony antibodies to $B S A$-colophony shown as a percentage of the binding obtained in the absence of colophony. Each point represents the mean ( $S E$ ) of triplicate readings.

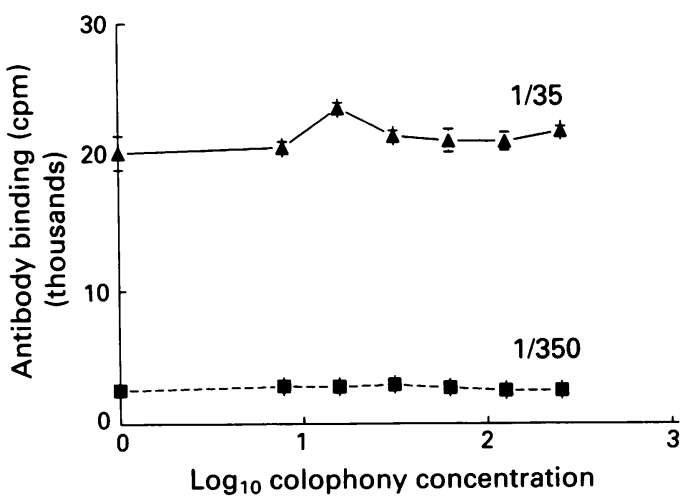

Figure 5 The effect of colophony solutions on the binding of guinea pig anti-BSA to $B S A$. Each point represents the mean $(S E)$ of triplicate readings.

\section{CELLULAR RESPONSES}

The proliferative responses of primed spleen cells to colophony-protein conjugates from two experiments are summarised in table 1 . Spleen cells from three mice in each treatment group were pooled in each experiment. Results, given only for the $50 \mu \mathrm{g} / \mathrm{ml}$ antigen concentration since this gave maximal stimulation, are expressed as a mitogenic index. The proliferative response of spleen cells primed with the BSA conjugate was poor, even to the specific antigen (BSA-colophony), although in experiment 1 the mitogenic index for this response was significantly greater than the indices from cultures containing the other challenge antigens ( $p=0.02$ or less). The proliferative response of the HIG-colophony primed cells to the HIG conjugate was more marked (mitogenic indices of 11.01 and 6.03 for experiments 1 and 2 respectively). There was also some reactivity to the HIG carrier protein itself (mitogenic indices 3.33 and $2 \cdot 64$ ).

\section{DERMAL SENSITIVITY TO COLOPHONY}

The application of DNFB to mouse flank skin resulted in a hypersensitive state as shown by the increase in ear thickness on subsequent challenge of the ears by painting with DNFB. The pooled results from two experiments are shown in table 2 . In contrast, colophony pretreatment of skin led to a slight overall increase in ear thickness on challenge but this did not differ significantly from that seen in mice treated with the acetone/oil vehicle alone ( 24 hours, $\mathrm{p}=0.21 ; 48$ hours, $\mathrm{p}=0.91$ ). A number of other procedures failed to produce sensitisation. These included pretreatment with cyclophosphamide to reduce any $T$ cell suppression, and multiple intradermal or subcutaneous injections of colophony in bicarbonate buffer over an extended period.

\section{Discussion}

We have shown that unconjugated colophony failed to produce specific antibody responses or dermal sensitisation in mice. It could be that either our procedure or the colophony dose used for skin sensitisation was inappropriate as skin hypersensitivity to colophony has been demonstrated in guinea pigs. ${ }^{11}$ However, anti- 
Table 1 Cellular immune responses to colophony-protein conjugates (triplicate observations)

\begin{tabular}{|c|c|c|c|c|c|c|c|c|c|}
\hline \multirow{4}{*}{ Immunising antigen } & \multirow{3}{*}{$\frac{\text { Experiment }}{1}$} & \multicolumn{8}{|c|}{ Mean (SE) mitogenic index $\star$ for spleen cell proliferation in response to: } \\
\hline & & \multicolumn{2}{|c|}{$B S A$-colophony } & \multicolumn{2}{|c|}{ HIG-colophony } & \multicolumn{2}{|c|}{$B S A$} & \multicolumn{2}{|c|}{$H I G$} \\
\hline & & $1 \cdot 78$ & $(0 \cdot 03)^{\star \star}$ & 1.08 & $(0 \cdot 05)$ & 0.98 & $(0 \cdot 08)$ & $0 \cdot 82$ & $(0 \cdot 05)$ \\
\hline & 2 & $1 \cdot 39$ & $(0.07)$ & $1 \cdot 24$ & $(0 \cdot 10)$ & $1 \cdot 02$ & $(0 \cdot 12)$ & 1.07 & $(0.08)$ \\
\hline HIG-colophony & 1 & $2 \cdot 14$ & $(0 \cdot 21)$ & 11.01 & $(0.64)^{\star \star}$ & 1.62 & $(0 \cdot 21)$ & $3 \cdot 33$ & $(0 \cdot 29)$ \\
\hline HIG-colophony & 2 & 1.07 & $(0.07)$ & 6.03 & $(0 \cdot 28)^{\star \star}$ & $2 \cdot 01$ & $(0 \cdot 32)$ & $2 \cdot 64$ & $(0.37)$ \\
\hline
\end{tabular}

${ }^{\star}$ Mitogenic index $=\frac{\text { counts in the presence of antigen }}{\text { counts in the absence of antigen }}$

$\star \star$ Results significantly different from others in the same row: $p \leqslant 0.02$.

BSA - bovine serum albumin; HIG-human immunoglobulin $\mathrm{G}$.

sera from mice and guinea pigs immunised with protein-colophony conjugates did recognise a component, or components, in Portuguese colophony. While we recognise that extrapolating from animal results to man cannot always be justified, it seems likely that colophony does have the potential to behave as a hapten in individuals exposed to colophony.

The mechanisms underlying the bronchoconstrictive and other respiratory effects caused by colophony are not known. Possible explanations include direct pharmacological action, non-specific irritation, and antibody mediated triggering of mast cells and macrophages. Pharmacological effects of colophony have not been reported. The time weighted threshold limit value for colophony pyrolysis products is a total aldehyde concentration of $0.1 \mathrm{mg} / \mathrm{m}^{3}$ (measured as formaldehyde) and is based on their capacity to cause irritation to the eyes and upper respiratory tract. ${ }^{12}$ This level is higher than those observed in an electronics factory where $22 \%$ of the shop floor workers experienced work related wheeze and/or breathlessness, ${ }^{1}$ suggesting an altered reactivity or immune response. This illustrates the need for an alternative to aldehyde concentration as an indicator of risk during exposure to colophony pyrolysis products-one which would better reflect the levels of resin acids and their derivatives which, as discussed below, appear to be mainly responsible for respiratory symptoms.

Bronchial provocation studies have confirmed the colophony specific nature of the asthma in workers exposed to soldering fumes. ${ }^{1314}$ However, there is no published evidence of specific immune responses to colophony in sensitised subjects. Neither colophony in solution $^{15}$ nor colophony conjugated to human serum albumin ${ }^{4}$ produced reactions in the skin prick test in workers with colophony asthma.

Table 2 Mean $(S D)$ percentage change in ear thickness in mice

\begin{tabular}{|c|c|c|}
\hline \multirow[b]{2}{*}{ Test agent } & \multicolumn{2}{|c|}{$\begin{array}{l}\% \text { increase in ear thickness } \\
\text { after: }\end{array}$} \\
\hline & 24 hours & 48 hours \\
\hline $\begin{array}{l}\text { DNFB }(n=12) \\
\text { Colophony }(n=12) \\
\text { Vehicle control }(n=10)\end{array}$ & $\begin{array}{rr}50 \cdot 57 & (16.68) \\
2.58 & (4.51) \\
0.24 & (4.04)\end{array}$ & $\begin{array}{rr}63.74 & (16.31) \\
1.22 & (4.93) \\
1.01 & (3.45)\end{array}$ \\
\hline
\end{tabular}

* Results pooled from two experiments.

DNFB-dinitrofluorobenzene.
Radioallergosorbent tests (RAST) with colophony-protein conjugates were also negative. ${ }^{4}$ The only immunological finding in these studies was that workers exposed to colophony in the electronics and solder making industries, whether or not they had asthma, had nonspecific increases in immunoglobulin levels, particularly of the IgM class. ${ }^{15}$ Such nonspecific elevations and other immunological perturbations have been observed in occupational groups exposed to respirable dusts such as coal ${ }^{16}$ and asbestos. ${ }^{17}$ These immunological effects may follow activation of macrophages by dusts, resulting in the enhanced production of interleukin- $1^{18}$ and other immunoregulatory factors. ${ }^{19}$ Preliminary studies from our laboratory which show that colophony can activate macrophages have been published in abstract form. ${ }^{20}$

The inability to detect specific antibodies in individuals sensitive to colophony may be a result of selecting an inappropriate protein, colophony component, or procedures for conjugation and in vitro testing. We have shown here that colophony can be immunogenic in animals eliciting both cell and antibody immunity, provided that it is bound to a carrier protein. The levels of specific anti-colophony activity, as determined in competitive binding assays, varied considerably from animal to animal. Thus, as with many other low molecular weight substances causing occupational asthma, colophony (or at least one of its components) can act as a hapten. The process by which colophony or its components bind to proteins in vivo is not known and, in fact, is obscure for chemical haptens in general. Colophony is insoluble in aqueous solutions at physiological $\mathrm{pH}$, but even when dissolved in sodium carbonate ( $\mathrm{pH} \mathrm{9.6)}$ it failed to produce immunogenic conjugates with proteins (Cullen and Hannant, unpublished data). The abietic acid molecule has two types of chemically reactive centres, the carboxyl group and the double bonds (figure 1). Fumes from a heated methyl ester of colophony (carboxyl group neutralised) caused considerably less fall in $\mathrm{FEV}_{1}$ than unmodified colophony. ${ }^{14}$ This suggested that the carboxyl group is important in protein binding and/or hapten recognition. In contrast, sensitised workers did react to fumes from a maleic modified glycerol ester of colophony where both types of reactive centre were neutralised. The implication of this finding is less clear since this compound also contained up to $25 \%$ of unreacted colophony. 
The relevance of our findings to the role of immune pathways in the development of asthma from colophony is that its components have the potential to act as haptens in man, although the apparent refractoriness of resin acids to produce immunogenic conjugates in the absence of relatively complex chemical manipulation in our study, together with the absence of any direct evidence of anti-colophony responses in workers sensitive to colophony, suggests the possibility that nonimmunological mechanisms might account for its observed respiratory effects. Perhaps a renewed search for evidence of immune responses in individuals sensitised to colophony would be worthwhile, although it would be prudent to use a panel of conjugates made from various colophony components and resin acid derivatives. Immune responses have been implicated in the pathogenesis of occupational asthma associated with another low molecular weight chemical, phthalic anhydride. ${ }^{56}$ Evidence that resin acids and not other components, such as esters of resin and fatty acids ${ }^{7}$ or breakdown products, are mainly responsible for respiratory symptoms derives from bronchial provocation studies ${ }^{14}$ and from observations that unheated colophony ${ }^{2}$ or colophony heated to temperatures which would not cause disruption of the acids ${ }^{15}$ could also cause sensitisation. However, a role for components volatile at room temperature cannot be excluded. In the provocation studies, ${ }^{14}$ sensitised workers reacted to both the colophony type (Portuguese Y) to which they had been exposed at work and to a commercial preparation of abietic acid. Unheated colophony is a well known cause of skin dermatitis and allergy and here too the resin acids have been traditionally implicated. ${ }^{11}$ However, the lack of a skin response in our experiments showed that colophony is not a potent dermal sensitiser compared with compounds such as DNFB. This is supported by the work of Karlberg and colleagues, which suggests that oxidation products of abietic and dehyroabietic acids are more potent skin sensitisers than abietic acid itself. $^{21} 22$

It is likely that these and many of the compounds produced through heating colophony, such as aldehydes, alcohols, and terpenes, are also capable of causing irritation and sensitisation in exposed workers. We are currently investigating the effects of fumes from heated colophony on rodents. Further work is required to establish which compounds are present in solder fumes and to determine their relative allergenicity.
We would wish to thank Dr John Corrie for helpful advice on conjugation techniques and the Asthma Research Council for financial support.

1 Burge PS, Perks W, O'Brien IM, Hawkins R, Green M. Occupational asthma in an electronics factory. Thorax 1979;34:13-8.

2 Burge PS, Wieland A, Robertson AS, Weir D. Occupational asthma due to unheated colophony. Br J Ind Med 1986; 43:559-60.

3 Hendy MS, Beattie BE, Burge PS. Occupational asthma due to an emulsified oil mist. Br J Ind Med 1985;42:51-4.

4 Burge PS. Occupational asthma, rhinitis, and alveolitis due to colophony. In: Pepys J, ed. Clinics in immunology and allergy: occupational respiratory allergy. London: WB allergy: occupational respir

5 Maccia CA, Bernstein IL, Emmett EA, Brooks SM. In vitro demonstration of specific IgE in phthalic anhydride hypersensitivity. Am Rev Respir Dis 1976;113:701-4.

6 Howe W, Venables KM, Topping MD, Dally MB, Hawkins R, Law SJ, et al. Tetrachlorophthalic anhydride asthma: evidence for specific IgE antibody.J Allergy Clin Immunol 1983;71:5-11.

7 Enos HI, Harris GC, Hedrick GW. Rosin and rosin derivatives. In: Kirk RE, Othmer DF, eds. Encyclopaedia of chemical technology. 3rd ed. New York: Wiley, 1968;17: 475-508.

8 Joye NM, Lawrence RV. Resin acid composition of pine oleoresins. J Chem Eng Data 1967;12:279-82.

9 Corrie JET, Hunter WM, Macpherson JS. A strategy for radioimmunoassay of plasma progesterone with use of a homologous-site 125-I labelled radioligand. Clin Chem 1981;27:594-9.

10 Hannant D, Donaldson K, Bolton R. Immunomodulatory effects of mineral dust. I. Effects of intraperitoneal dust inoculation on splenic lymphocyte function and humoral immune responses in vivo. J Clin Lab Immunol 1985;16: immune

11 Karlberg A-T, Boman A, Wahlberg JE. Allergenic potential of abietic acid, colophony and pine resin-HA. Contact Dermatitis 1980;6:481-7.

12 American Conference of Government Industrial Hygienists. Documentation of the threshold limit values for substances in workroom air. 5th ed. 1986:514.

13 Fawcett IW, Newman Taylor AJ, Pepys J. Asthma due to inhaled chemical agents-fumes from "Multicore" soldering flux and colophony resin. Clin Allergy 1976;6: 577-85.

14 Burge PS, Harries MG, O'Brien I, Pepys J. Bronchial provocation studies in workers exposed to the fumes of electronic soldering fluxes. Clin Allergy 1980;10:137-49.

15 Burge PS, Edge G, Hawkins R, White V, Newman Taylor AJ. Occupational asthma in a factory making flux-cored solder containing colophony. Thorax 1981;36:828-34.

16 Robertson MD, Boyd JE, Fernie JM, Davis JMG. Some immunological studies on coalworkers with and without pneumoconiosis. Am J Indust Med 1983;4:467-76.

17 Lange A. An epidemiological survey of immunological abnormalities in asbestos workers. I. Non-organ and organ specific auto-antibodies II. Serum Ig levels. Environ Res 1980;22:176-83.

18 Kusaka Y, Cullen RT, Donaldson K. Experimental studies on the effect on the immune system of exposure to coalmine dust and quartz. Proceedings of VII International Conference on Pneumoconiosis, Pitsburgh, 1988. US Department of Health and Human Services, 1990: 1345-50.

19 Donaldson K, Davis JMG, James K. Asbestos-activated peritoneal macrophages release a factor(s) which inhibits lymphocyte mitogenesis. Environ Res 1984;35:104-14

20 Cullen RT, Johnston P, Brown G, Soutar CA. Immunomodulation by colophony, an agent causing occupational asthma. Thorax 1987;42:726.

21 Karlberg A-T, Bergstedt E, Boman A, Bohlinder K, Liden $\mathrm{C}$, Nilsson JLG, et al. Is abietic acid the allergenic component of colophony? Contact Dermatitis 1985;13:209-15.

22 Karlberg A-T, Wahlberg JE. Identification of contact allergens in colophony. Scand J Work Environ Health 1988;14 (suppl 1):80-1. 